\title{
Excess Body Mass Index and Risk of Liver Cancer: A Nonlinear Dose-Response Meta-Analysis of Prospective Studies
}

\author{
Rui Rui ${ }^{1,2}$, Jiao Lou ${ }^{2}$, Li Zou ${ }^{2}$, Rong Zhong ${ }^{2}$, Ji Wang ${ }^{3}$, Ding Xia ${ }^{1}$, Qi Wang ${ }^{1}$, Heng Li ${ }^{1}$, Jing Wu ${ }^{2}$, Xuzai Lu ${ }^{2}$, \\ Chuanqi $\mathrm{Li}^{4}$, Li Liu ${ }^{5}$, Jiahong $\mathrm{Xia}^{6}$, Hua Xu${ }^{1 *}$
}

1 Department of Urology, Tongji Hospital, Tongji Medical College, Huazhong University of Science and Technology, Wuhan, China, 2 Department of Epidemiology and Biostatistics and MOE Key Lab of Environment and Health, School of Public Health, Tongji Medical College, Huazhong University of Science and Technology, Wuhan, China, 3 Department of Urology and Helen-Diller Comprehensive Cancer Center, University of California San Francisco, San Francisco, California, United States of America, 4 School of Medicine and Health Management, Tongji Medical College, Huazhong University of Science and Technology, Wuhan, China, 5 Department of Epidemiology and Biostatistics and Guangdong Key Lab of Molecular Epidemiology, Guangdong Pharmaceutical University, Guangzhou, China, 6 Department of Cardiovascular Surgery, Union Hospital, Huazhong University of Science and Technology, Wuhan, China

\begin{abstract}
Background: Excess body weight measured as body mass index (BMI) has a positive association with risk of common cancers. However, previous meta-analyses related to BMI and liver cancer had inconsistent results. The purpose of the current study is to establish a nonlinear dose-response relationship between BMI and incidence risk of liver cancer.

Methods: A systematic literature search for relevant articles published from 1966 to November 2011 was conducted in PUBMED and EMBASE digital databases. Additional articles were manually searched by using the reference lists of identified papers. Restricted cubic splines and generalized least-squares regression methods were used to model a potential curvilinear relationship and to make a dose-response meta-analysis. Stratified analysis, sensitivity analysis and assessment of bias were performed in our meta-analysis.

Results: 8 articles including 1,779,471 cohort individuals were brought into meta-analysis. A non-linear dose-response association between BMI and risk of liver cancer was visually significant ( $P$ for nonlinearity $<0.001$ ), besides, the point value of $\mathrm{BMI}$ also enhanced the results quantitatively, where relative risks were $1.02(95 \% \mathrm{Cl}=1.02-1.03), 1.35(95 \% \mathrm{Cl}=1.24-1.47)$ and 2.22 -fold $(95 \% \mathrm{Cl}=1.74-2.83)$ when $\mathrm{BMI}$ was at the point of 25,30 and $35 \mathrm{~kg} / \mathrm{m}^{2}$ compared with reference (the median value of the lowest category), respectively. The ethnicity of the population was found as the main source of heterogeneity. In subsequent stratified analysis, no evidence of heterogeneity was showed in Asian and White populations ( $P$ for heterogeneity $>0.1$ ), and all value of BMI still presented significantly increased risk of cancer.
\end{abstract}

Conclusions: The findings from meta-analysis provided that excess BMI had significant increased association with risk of liver cancer, although the biological mechanisms underlying the obesity-cancer link still need to be clarified.

Citation: Rui R, Lou J, Zou L, Zhong R, Wang J, et al. (2012) Excess Body Mass Index and Risk of Liver Cancer: A Nonlinear Dose-Response Meta-Analysis of Prospective Studies. PLoS ONE 7(9): e44522. doi:10.1371/journal.pone.0044522

Editor: Xiao-Ping Miao, MOE Key Laboratory of Environment and Health, School of Public Health, Tongji Medical College, Huazhong University of Science and Technology, China

Received May 26, 2012; Accepted August 8, 2012; Published September 18, 2012

Copyright: $(\subset) 2012$ Rui et al. This is an open-access article distributed under the terms of the Creative Commons Attribution License, which permits unrestricted use, distribution, and reproduction in any medium, provided the original author and source are credited.

Funding: This work was supported by fundamental research funds for Huazhong University of Science and Technology (HUST: NO. 2011TS019). The funders had no role in study design, data collection and analysis, decision to publish, or preparation of the manuscript.

Competing Interests: The authors have declared that no competing interests exist.

*E-mail: xuhuawhu@163.com

\section{Introduction}

Primary liver cancer is the sixth most common cancer in the world, with an estimated incidence of 564,000 per year [1]. Since most patients in early of liver cancer have no obvious symptoms, liver cancer is usually diagnosed in the later stages and has a dismal prognosis with an average 5-year survival rate of $6-11 \%$, making it the third leading cause of cancer mortality worldwide [2]. Given that there are no established screening methods for early detection and no better treatments to prolong survival time, the identification of modifiable risk factors for the primary prevention against liver cancer is of considerable public health importance.

Epidemiological studies have identified chronic Hepatitis B or C viral (HBV or $\mathrm{HCV}$ ) infection, alcohol consumption, cigarette smoking, and aflatoxin exposure as important risk factors for liver cancer [2-4]. Meanwhile, other suspected risk factors, such as obesity, diet, insulin resistance, use of oral contraceptives, and iron overload, still need to be clarified [5], of which, obesity [Body mass index, (BMI) $\left.\geq 30 \mathrm{~kg} / \mathrm{m}^{2}\right]$ has been raised by accumulating evidence to be associated with the increased risk of liver cancer $[6,7]$. In the context of cirrhosis, obesity has been an independent risk factor for the development of hepatocellular carcinoma [4]; 
moreover, diabetes, as a closely correlated factor with obesity in the composition of metabolic syndrome, has been suggested to be independent risk factor of liver cancer [8]. All these evidences suggested a key role of obesity associated with liver cancer.

However, reports on the association between obesity and risk of liver cancer are still controversial. For instance, a large-scale in Asia-Pacific [9] showed no clear associations between BMI and risk of liver cancer, as well as other three studies [10-12] in Australia, Japan and the Unite State, respectively. Even the three meta-analyses so far performed on obesity and liver cancer risk also yielded inconsistent results. In the two meta-analyses on both liver cancer incidence and mortality suggested that BMI was associated with an increased risk of liver cancer in both males and females [13,14]; whereas the third meta-analysis of liver cancer incidence, Renehan et al. found no significant association [15]. The divergent results between these meta-analyses may due to the nonlinear association between BMI with liver cancer risk and the heterogeneity by merging liver cancer mortality and incidence together. Although it has been hypothesized that excess BMI can increase liver cancer risk, none of the previous meta-analyses have examined the shape of the dose-response relationship by conducting nonlinear dose response analyses. Considering recent evidence showed a nonlinear relation between BMI and pancreatic cancer, we hypothesized a nonlinear association also existed in $\mathrm{BMI}$ and liver cancer risk [16]. As a result, we summarized the published prospective studies on incidence risk of liver cancer to update the previous meta-analysis and performed a dose-response meta-analysis as described by Larsson et al. [17] to investigate a potential nonlinear association between BMI and liver cancer risk.

\section{Materials and Methods}

\section{Search strategy and selection criteria}

A systematic literature search for relevant articles on body mass index (BMI) in humans and risk of liver cancer published from 1966 to November 2011 was conducted in PUBMED and EMBASE databases with a search strategy that combined text words: "obesity, weight, overweight, body mass index, BMI or body size" and "liver cancer, liver tumor or hepatocellular carcinoma" without language restriction. In addition, we manually searched the reference lists of retrieved articles to identify additional articles.

Studies were eligible for inclusion in this meta-analysis if they satisfied the following criteria: 1) the prospective study evaluated the relationship between BMI and the risk of liver cancer; 2) the outcome was liver cancer incidence; 3) the exposure of interest was the BMI for 3 or more quantitative categorized level; 4) the study reported relative risks with 95\% confidence intervals (CIs) for each BMI category. Studies on gallbladder cancer, hepatic adenomas, and other subtypes of liver cancer were excluded. When multiple studies shared the same population, only the one with the most detailed information of outcome or the largest sample size was included.

\section{Data extraction}

Data were extracted independently and in duplicate by 2 reviewers (RUI and LOU). For each study, the following data were extracted from the published article: first author's name, publication year, study location, ethnicity of population, followup years, age, measure method of BMI, sample size of gender, BMI categories and risk estimate for each BMI category, and covariates adjusted for multivariable analysis. Unless otherwise indicated, ethnicity was assumed to correspond to the geographic location where subjects were selected. We extracted the relative risks with their 95\% CIs that reflected the greatest degree of adjustment for potential confounders.

For every study, the midpoint of the upper and lower boundaries in each category was assigned as median BMI to each corresponding relative risk. If the upper boundary for the highest category was not reported (such as BMI $\geq 30 \mathrm{~kg} / \mathrm{m}^{2}$ ), the range of the highest boundary was set as the same amplitude as the adjacent category [17]. The categories of $\mathrm{BMI}<18.5$ were excluded as a convenient way to evaluate the association between excess BMI and liver cancer, and then, the midpoint of the lowest category was regarded as a reference level.

\section{Statistical analysis}

A dose-response meta-analysis was performed to examine a potential nonlinear relationship between BMI and liver cancer. We used restricted cubic splines with 3 knots at fixed 5\%, 50\% and $95 \%$ to model a potential curvilinear relationship [18] and then a dose-response meta-analysis was conducted using generalized least-squares regression, taking into account the trend estimation of summarized data across multiple studies as described by Orsini et al [19]. The method requires the distribution of case and person-years and median level of BMI in each category to the corresponding relative risk for each study (the relative risks with estimates for at least 3 quantitative exposure categories are known). Between-study heterogeneity was assessed by the $Q$ statistic test. Heterogeneity was considered significant when $P<0.1$ for the $Q$ statistic [20]. DerSimonian and Laird random-effects models [21] were applied when heterogeneity was significant; otherwise, a fixed-effects model was applied. The pooled relative risks for specific exposure values were finally estimated (per $0.5 \mathrm{~kg} / \mathrm{m}^{2}$ increase from $\mathrm{BMI}=18.5$ to $35 \mathrm{~kg} / \mathrm{m}^{2}$ ) using a procedure described by Orsini and Greenland compared with the lowest exposure value of BMI [22]. A test for a nonlinearity relationship between BMI and liver cancer was calculated by making the second spline equal to zero [17]. To test and verify the non-linear model, in separate analyses, we pooled the relative risks for comparable categories of BMI as compared with the lowest category under common linear method, classifying the BMI into 3 groups: $18.5-25 \mathrm{~kg} / \mathrm{m}^{2}$ (reference), $25-30 \mathrm{~kg} / \mathrm{m}^{2}$, and $\geq 30 \mathrm{~kg}$ / $\mathrm{m}^{2}$. To explore potential sources of between-study heterogeneity, further stratified analyses, if feasible, were conducted by gender (male, female or combined male and female), ethnicity of population (Asian or White), measured methods for BMI (measured or self-reported BMI), separately. Additionally, sensitivity analysis was performed by omitting each article in turn to determine the influence of each study on the overall estimate [23]. Publication bias was evaluated by Egger's test [24]. All statistical analyses were performed in STATA software (version 10.1), and a 2-sided $P$ value of less than 0.05 was considered significant.

\section{Results}

\section{Studies characteristics}

As shown by Figure S1, 35 of 1,372 initial articles were identified for full-text review. The reports by Jee et al. and $\mathrm{Oh}$ et al. shared the overlapping samples, and the report by Jee et al. was selected with completed information [25,26]. Five articles of mortality [12,27-30] and another four articles [31-34] included in previous meta-analyses were excluded for insufficient data of BMI category. Finally, a total of 8 articles with 12 studies met the inclusion criteria to be included in our meta-analysis $[10,11,26,35-$ 39].

All articles were published in English and more than half of the articles (6/8) were published after the year 2006. Analyses of 
Table 1. Characteristics for prospective studies of body mass index and risk of liver cancer included in a meta-analysis.

\begin{tabular}{|c|c|c|c|c|c|c|c|c|c|c|c|}
\hline \multirow[t]{2}{*}{ Study } & \multirow{2}{*}{$\frac{P,}{\text { year }^{a}}$} & \multirow{2}{*}{ Location } & \multirow[t]{2}{*}{ Race $^{b}$} & \multirow{2}{*}{$\frac{F,}{\text { yearc }^{c}}$} & \multirow[t]{2}{*}{ Age } & \multirow[t]{2}{*}{$M^{d}{ }^{d}$} & \multicolumn{2}{|c|}{ No. of case } & \multirow{2}{*}{$\frac{\text { BMI }}{\left(\mathrm{kg} / \mathrm{m}^{2}\right)}$} & \multirow{2}{*}{$\begin{array}{l}\text { Relative risk } \\
\text { with } 95 \% \mathrm{Cl}\end{array}$} & \multirow[t]{2}{*}{ Adjustments } \\
\hline & & & & & & & Male & Female & & & \\
\hline Kuriyama & 2005 & Japan & A & 9 & $>40$ & $\mathrm{~s}$ & 69 & 31 & & Male: & Age, smoking, \\
\hline \multirow[t]{7}{*}{ [10] } & & & & & & & & & $18.5-24.9$ & 1.00 Reference & meat, vegetables, \\
\hline & & & & & & & & & $25.0-27.4$ & $1.30(0.54,3.16)$ & alcohol intake, \\
\hline & & & & & & & & & $27.5-29.9$ & $0.91(0.30,2.80)$ & bean-paste soup, \\
\hline & & & & & & & & & & Female: & type of health \\
\hline & & & & & & & & & $18.5-24.9$ & 1.00 Reference & insurance \\
\hline & & & & & & & & & $25.0-27.4$ & $0.80(0.40,1.63)$ & \\
\hline & & & & & & & & & $27.5-29.9$ & $1.14(0.46,2.87)$ & \\
\hline \multirow[t]{4}{*}{ Rapp [11] } & 2005 & Austria & W & 9.9 & Male: & M & 57 & & & Male: & Age, smoking, \\
\hline & & & & & 41.8 & & & & $18.5-24.9$ & 1.00 Reference & occupational \\
\hline & & & & & Female & & & & $25.0-29.9$ & $1.32(0.73,2.37)$ & group \\
\hline & & & & & 42.5 & & & & $30-34.9$ & $1.67(0.75,3.72)$ & \\
\hline \multirow[t]{12}{*}{ Jee [26] } & 2008 & Korean & A & 10.8 & Male: & $\mathrm{M}$ & 8759 & 1761 & & Male: & Age, gender, \\
\hline & & & & & 45.0 & & & & $<20$ & $0.90(0.81,1.00)$ & smoking status \\
\hline & & & & & Female & & & & $20-22.9$ & $0.97(0.90,1.04)$ & \\
\hline & & & & & 49.4 & & & & $23.0-24.9$ & 1.00 Reference & \\
\hline & & & & & & & & & $25.0-29.9$ & $1.04(0.96,1.13)$ & \\
\hline & & & & & & & & & $\geq 30$ & $1.63(1.27,2.10)$ & \\
\hline & & & & & & & & & & Female: & \\
\hline & & & & & & & & & $<20$ & $0.85(0.67,1.06)$ & \\
\hline & & & & & & & & & $20-22.9$ & $0.76(0.64,0.91)$ & \\
\hline & & & & & & & & & $23.0-24.9$ & 1.00 Reference & \\
\hline & & & & & & & & & $25.0-29.9$ & $1.14(0.97,1.35)$ & \\
\hline & & & & & & & & & $\geq 30$ & $1.39(1.00,1.94)$ & \\
\hline \multirow[t]{15}{*}{ Chen [35] } & 2008 & Taiwan & A & 14 & NA & M & 222 & 69 & & $\mathrm{HBV}(-), \mathrm{HCV}(-):$ & Age, education, \\
\hline & & & & & & & & & $<23$ & 1.00 Reference & gender, smoking, \\
\hline & & & & & & & & & $23-24.9$ & $0.88(0.41,1.86)$ & alcohol intake \\
\hline & & & & & & & & & $25-29.9$ & $0.86(0.42,1.74)$ & \\
\hline & & & & & & & & & $\geq 30$ & $2.36(0.91,6.17)$ & \\
\hline & & & & & & & & & & $\operatorname{HBV}(+), \operatorname{HCV}(-):$ & \\
\hline & & & & & & & & & $<23$ & 1.00 Reference & \\
\hline & & & & & & & & & $23-24.9$ & $1.40(0.97,2.02)$ & \\
\hline & & & & & & & & & $25-29.9$ & $1.17(0.81,1.69)$ & \\
\hline & & & & & & & & & $\geq 30$ & $1.36(0.64,2.89)$ & \\
\hline & & & & & & & & & & $\operatorname{HBV}(-), \operatorname{HCV}(+):$ & \\
\hline & & & & & & & & & $<23$ & 1.00 Reference & \\
\hline & & & & & & & & & $23-24.9$ & $1.05(0.41,2.73)$ & \\
\hline & & & & & & & & & $25-29.9$ & $3.02(1.48,6.14)$ & \\
\hline & & & & & & & & & $\geq 30$ & $4.13(1.38,12.4)$ & \\
\hline loannou ${ }^{e}$ & 2007 & USA & W & 3.6 & NA & M & Total: 100 & & Total: & Age, HCV & \\
\hline \multirow[t]{3}{*}{ [36] } & & & & & & & & & $<25$ & 1.00 Reference & infection, $\mathrm{HBsAg}$ \\
\hline & & & & & & & & & $25-30$ & $2.80(1.40,5.40)$ & \\
\hline & & & & & & & & & $\geq 30$ & $2.50(1.30,4.90)$ & \\
\hline Nkontchou ${ }^{e}$ & 2006 & France & w & 4.2 & 61.4 & M & Total: 220 & & Total: & Age,sex, diabetes, & \\
\hline \multirow[t]{4}{*}{ [37] } & & & & & & & & & $<25$ & 1.00 Reference & cirrhosis cause, \\
\hline & & & & & & & & & $25-30$ & $2.00(1.40,2.70)$ & alcohol intake, \\
\hline & & & & & & & & & $\geq 30$ & $2.80(2.00,4.00)$ & hepatitis infection \\
\hline & & & & & & & & & & & status \\
\hline Samanic & 2006 & Sweden & W & 19 & 34.3 & M & 194 & & & Male: & Age, smoking, \\
\hline
\end{tabular}


Table 1. Cont.

\begin{tabular}{|c|c|c|c|c|c|c|c|c|c|c|c|}
\hline \multirow[t]{2}{*}{ Study } & \multirow{2}{*}{$\frac{P,}{\text { year }^{a}}$} & \multirow[t]{2}{*}{ Location } & \multirow[t]{2}{*}{ Race $^{\mathbf{b}}$} & \multirow{2}{*}{$\frac{F,}{\text { yearc }^{c}}$} & \multirow[t]{2}{*}{ Age } & \multirow[t]{2}{*}{$M^{d}$} & \multicolumn{2}{|c|}{ No. of case } & \multirow{2}{*}{$\frac{B M I}{\left(\mathrm{~kg} / \mathrm{m}^{2}\right)}$} & \multirow{2}{*}{$\begin{array}{l}\text { Relative risk } \\
\text { with } 95 \% \mathrm{Cl}\end{array}$} & \multirow[t]{2}{*}{ Adjustments } \\
\hline & & & & & & & Male & Female & & & \\
\hline \multirow[t]{3}{*}{ [38] } & & & & & & & & & $18.5-24.9$ & 1.00 Reference & calendar year \\
\hline & & & & & & & & & $25.0-29.9$ & $1.45(1.06,1.98)$ & \\
\hline & & & & & & & & & $>30$ & $3.13(2.04,4.79)$ & \\
\hline $\mathrm{Yu}^{\mathrm{e}}$ & 2008 & Taiwan & A & 14.7 & $18-60$ & M & 134 & & & Male: & Age, cigarette \\
\hline \multirow[t]{4}{*}{ [39] } & & & & & & & & & $<18.5$ & $1.55(0.49,4.93)$ & smoking, alcohol \\
\hline & & & & & & & & & $18.5-24.9$ & 1.00 Reference & consumption, \\
\hline & & & & & & & & & $25.0-29.9$ & $1.48(1.04,2.12)$ & history of diabetes \\
\hline & & & & & & & & & $\geq 30$ & $1.96(0.72,1.64)$ & \\
\hline
\end{tabular}

Abbreviations: NA, no available; HBV $(+) /(-)$, hepatitis b virus infection positive/negative; $\mathrm{HCV}(+) /(-)$, hepatitis c virus infection positive/negative.

${ }^{\mathrm{a} P}$, years means Publication year.

${ }^{\mathrm{b}} \mathrm{A}$ refers to Asian and $\mathrm{W}$ refers to White.

${ }^{C} F$, years means Follow-up years.

${ }^{\mathrm{d}} \mathrm{MM}$ means Measure Methods, $\mathrm{M}$ refer to measured BMI directly and $\mathrm{S}$ refers to self-reported BMI.

${ }^{\mathrm{e} C}$ Cohort studies were conducted in patients with cirrhosis cohort.

doi:10.1371/journal.pone.0044522.t001

relative risks for BMI were performed separately for males and females in 2 articles $[10,26]$ and thus were considered as independent studies. The general population, HCV-based and HBV-based populations in the article by Chen et al. were also considered separately [35]. In total, this meta-analysis included 12 independent prospective studies of 1, 779, 471 cohort individuals, the durations of follow-up varied from 3.6 years to 19 years across the included studies (Table 1). 8 studies were performed for Asian, and 4 studies were for White population. 10 studies collected measured BMI, and 2 study collected self-reported data. Most studies provided relative risk estimates that were adjusted by age $(\mathrm{n}=12)$, cigarette smoking $(\mathrm{n}=10)$, and alcohol consumption $(n=5)$. Additionally, 3 cohort studies were conducted in persons with cirrhosis $[36,37,39]$.

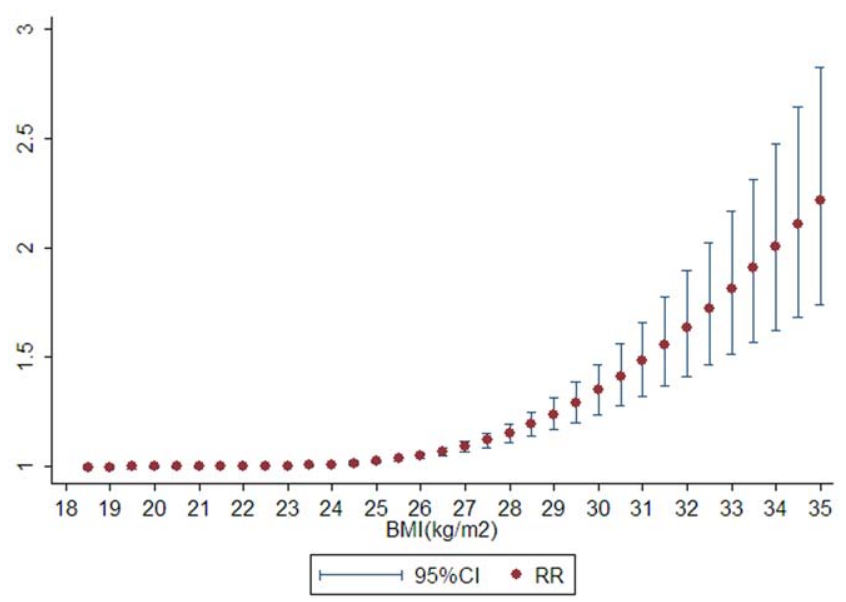

Figure 1. Nonlinear dose-response analyses of body mass index and relative risk of liver cancer in meta-analysis. $(P$ heterogeneity $=0.001 ; P$-non-linear $<0.001$ ).

doi:10.1371/journal.pone.0044522.g001
Overall dose-response association between $\mathrm{BMI}$ and risk of liver cancer

Significant heterogeneity was observed across studies $(P$ for heterogeneity $<0.001)$, and thus the random-effects model was applied. There was a significant nonlinear dose-response association visually between BMI and risk of liver cancer $(P$ for nonlinear $<0.001$, Figure 1) with a significantly increased trend of relative risk as per $0.5 \mathrm{~kg} / \mathrm{m}^{2}$ increase in BMI. Several representative point value enhanced the association: the point estimate of $\mathrm{BMI}$ at $25 \mathrm{~kg} / \mathrm{m}^{2}$ had a modest increased risk of liver cancer 1.02 $(95 \%$ CI $=1.02-1.03)$, while $30 \mathrm{~kg} / \mathrm{m}^{2}$ and $35 \mathrm{~kg} / \mathrm{m}^{2}$ both conferred significantly increased cancer relative risks of 1.35 $(95 \% \mathrm{CI}=1.24-1.47)$ and $2.22(95 \% \mathrm{CI}=1.74-2.83)$, indicating a significant and evolutionary risk of liver cancer along with BMI increasing. Egger's test showed a modest publication bias, with a $P$ value of 0.03 (Figure 2).

When we pooled the relative risks for comparable categories of $\mathrm{BMI}$ in a separate analysis under linear model, the relative risks of liver cancer were $1.13(95 \% \mathrm{CI}=1.05-1.21)$ for $\mathrm{BMI}=25-30 \mathrm{~kg} /$ $\mathrm{m}^{2}$ and $2.09(95 \% \mathrm{CI}=1.72-2.45)$ for $\mathrm{BMI} \geq 30 \mathrm{~kg} / \mathrm{m}^{2}$, suggest-

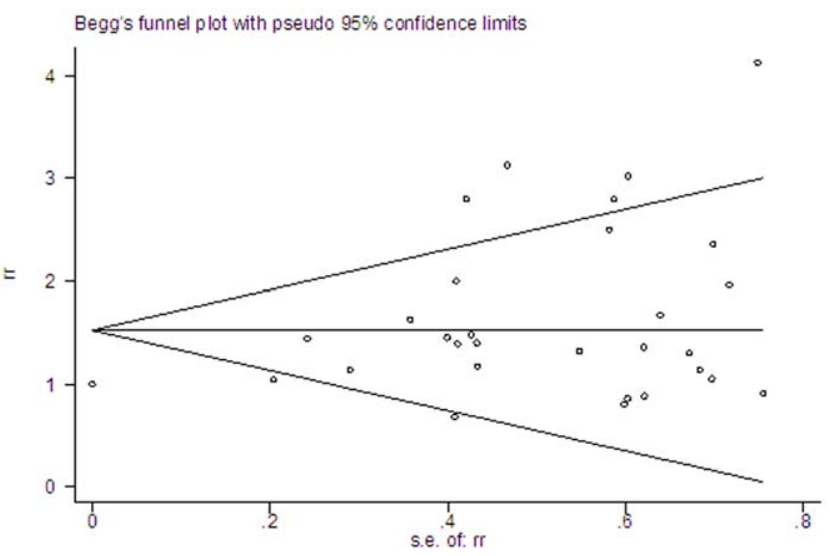

Figure 2. Publication bias in the studies included in this metaanalysis.

doi:10.1371/journal.pone.0044522.g002 


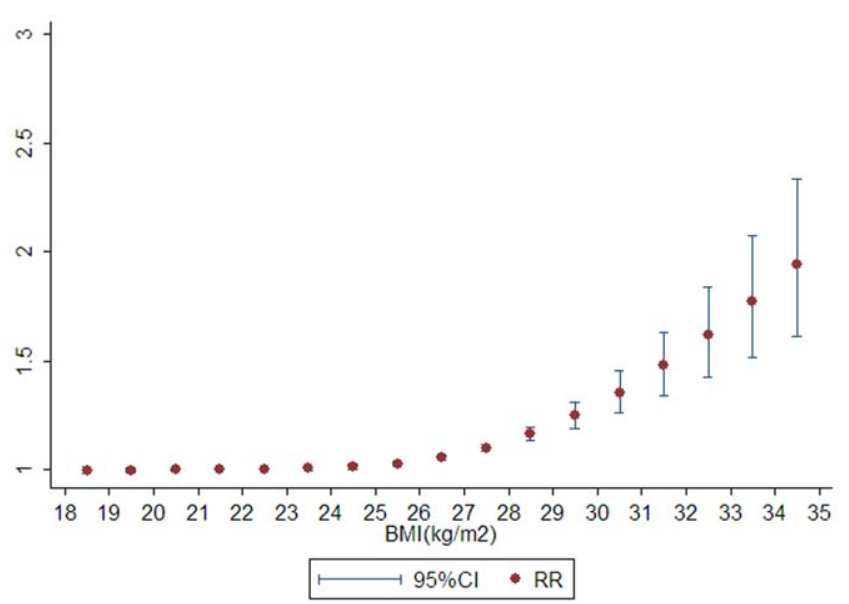

Figure 3. The curve of body mass index and relative risk of liver cancer in Asian population. doi:10.1371/journal.pone.0044522.g003

ing the linear method present the similar trend as our non-linear results.

After excluding the 3 articles of cirrhosis cohort, a significant nonlinear dose-response relationship was still found between BMI and risk of liver cancer $(P$ for nonlinear $<0.001)$, the relative risks were $1.01(95 \% \mathrm{CI}=1.00-1.02), 1.27(95 \% \mathrm{CI}=1.17-1.38)$ and $2.10(95 \% \mathrm{CI}=1.61-2.74)$ at 25,30 and $35 \mathrm{~kg} / \mathrm{m}^{2}$, respectively.

\section{Subgroup analyses between BMI and the risk of liver cancer}

Specific data for the association between BMI and liver cancer were stratified on the basis of sex into 2 subgroups: studies on males $(\mathrm{n}=6)$ and females $(\mathrm{n}=2)$. In males, between-study heterogeneity still existed $(P$ for heterogeneity $<0.001)$. A significant dose-response effect was observed for BMI with liver cancer risk in male $(P$ for nonlinear $<0.001$; Figure $S 2)$, and the point value of $\mathrm{BMI}$ at 30 and $35 \mathrm{~kg} / \mathrm{m}^{2}$ yielded significant relative risks of $1.51(95 \% \mathrm{CI}=1.35-1.70)$ and $2.57(95 \% \mathrm{CI}=1.95-3.38)$. However, there were insufficient female samples to form restricted cubic splines to establish nonlinear model, so the stratified analysis on females failed.

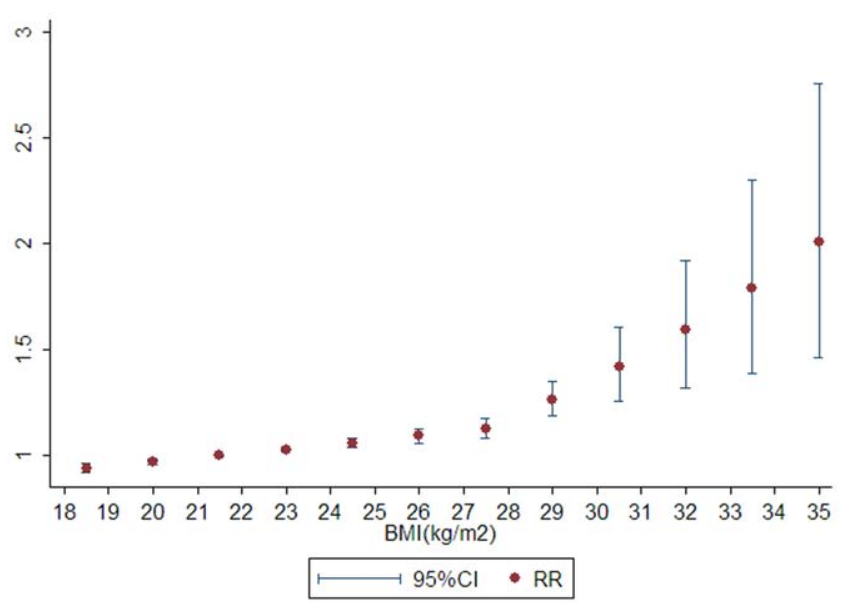

Figure 4. The curve of body mass index and relative risk of liver cancer in White population. doi:10.1371/journal.pone.0044522.g004
After stratifying by ethnicity (Figure 3 and Figure 4), heterogeneity was totally removed by Asian and White subgroup, and a significant nonlinear dose-response relationship between BMI and risk of liver cancer was observed in both ethnicity ( $P$ for nonlinear $<0.001 ; P$ for heterogeneity $=0.470$ and 0.119 , receptively).

According to the methods of obtaining BMI, analysis was only performed in the subgroup of reporting measured BMI. Despite the nonlinear relationship existed $(P$ for nonlinear $<0.001)$, there no statistically significance between BMI and liver cancer under measured BMI subgroup with significant heterogeneity $(P$ for heterogeneity $=0.032)($ Figure S3).

\section{Sensitivity analysis}

Considering the presentation of heterogeneity, sensitivity analysis was performed by excluding each report in turn. Before and after removal of each report, a significant nonlinear doseresponse relationship between BMI and risk of liver cancer still remained and the point estimation of BMI at 25, 30, and $35 \mathrm{~kg}$ / $\mathrm{m}^{2}$ did not substantially change (Table 2), suggesting a high stability for the current result.

\section{Discussion}

Previously, to summarize the publications on excess BMI and risk of liver cancer, two meta-analyses have been conducted, both based on the data assessing liver cancer incidence and mortality, and another meta-analysis focused on liver cancer incidence included five articles. In this current work, 12 prospective studies on the incidence of liver cancer were included. Then a doseresponse meta-analysis was applied by increasing every $0.5 \mathrm{~kg} / \mathrm{m}^{2}$ from the value of $\mathrm{BMI}=18.5$ to fit an accurate relationship with risk of liver cancer. Therefore, current findings produced a persuasive comprehending conclusion that a non-linear doseresponse association existed between BMI and incidence risk of liver cancer: the greater increased by the value of BMI, the higher risk produced by liver cancer. Several representative point value enhanced the association: not only was the point of BMI at $35 \mathrm{~kg} /$ $\mathrm{m}^{2}$ associated with liver cancer, with the highest 2.22-fold risk (95\% CI $=1.74-2.83)$, but also BMI equal to $30 \mathrm{~kg} / \mathrm{m} 2$ still yielded a 1.35 -fold $(95 \% \mathrm{CI}=1.24-1.47)$ increased risk compared with reference BMI (the median value of lowest category).

Significant heterogeneity existed in our meta-analysis as expected. We examined in more detail which factors contributed to significant heterogeneity by sensitivity and stratified analysis. The ethnic background appeared to be the critical sources of heterogeneity. Obesity has increased in many North American and European populations over the past three decades; more than $21.9 \%$ adults in the United States and the United Kingdom were obese, and the rates for Asian population generally lagged behind [40]. In our meta-analysis, White population had higher risk than Asian at same point of BMI. The possible explanation might be that the White had a higher percentage of body fat per BMI category than individuals of Asian. Even in the same ethnic group, BMI-body-fat association showed heterogeneity [41]. This was an important consideration given that the correlation between BMI and risk of liver cancer might differ across diverse ethnic backgrounds.

The previous meta-analyses all indicated that males were at higher risk of developing liver cancer than females, however, due to insufficient female samples to form restricted cubic splines to establish nonlinear model, we only found the significant association between BMI with liver cancer in males. The results of males came to a similar estimate as SC Larsson: relative risks were 2.42 $(95 \% \mathrm{CI}=1.83-3.20)$ and $2.46(95 \% \mathrm{CI}=1.91-3.18)$, respectively. 
Table 2. Relative risk with $95 \% \mathrm{Cl}$ of body mass index $\left(\mathrm{kg} / \mathrm{m}^{2}\right)$ at point of 25,30 and 35 in comparison with reference (median value of lowest category) by omitting each article in sensitivity analysis.

\begin{tabular}{|c|c|c|c|c|c|c|c|c|}
\hline \multirow[t]{2}{*}{ Omitted study } & \multicolumn{2}{|c|}{$\mathrm{BMI}=25 \mathrm{~kg} / \mathrm{m}^{2}$} & \multicolumn{2}{|c|}{$\mathrm{BMI}=30 \mathrm{~kg} / \mathrm{m}^{2}$} & \multicolumn{2}{|c|}{$\mathrm{BMI}=35 \mathrm{~kg} / \mathrm{m}^{2}$} & \multirow[t]{2}{*}{$P^{*}$} & \multirow[t]{2}{*}{$P^{* *}$} \\
\hline & $\mathbf{R R}$ & $95 \% \mathrm{Cl}$ & $\mathbf{R R}$ & $95 \% \mathrm{Cl}$ & RR & $95 \% \mathrm{Cl}$ & & \\
\hline Kuriyama [10] & 1.02 & $1.02-1.03$ & 1.33 & $1.23-1.44$ & 2.15 & $1.72-2.70$ & $<0.001$ & $<0.001$ \\
\hline Rapp [11] & 1.02 & $1.02-1.03$ & 1.34 & $1.24-1.45$ & 2.18 & $1.73-2.74$ & $<0.001$ & $<0.001$ \\
\hline Jee [26] & 1.01 & $1.01-1.02$ & 1.29 & $1.20-1.38$ & 2.11 & $1.69-2.63$ & $<0.001$ & $<0.001$ \\
\hline Chen [35] & 1.02 & $1.01-1.03$ & 1.34 & $1.24-1.45$ & 2.18 & $1.73-2.74$ & $<0.001$ & $<0.001$ \\
\hline loannou [36] & 1.02 & $1.02-1.03$ & 1.36 & $1.25-1.47$ & 2.27 & $1.79-2.87$ & $<0.001$ & $<0.001$ \\
\hline Nkontchou [37] & 1.02 & $1.01-1.03$ & 1.31 & $1.21-1.43$ & 2.07 & $1.62-2.65$ & $<0.001$ & $<0.001$ \\
\hline Samanic [38] & 1.02 & $1.01-1.03$ & 1.30 & $1.20-1.41$ & 2.00 & $1.57-2.53$ & $<0.001$ & $<0.001$ \\
\hline Yu [39] & 1.04 & $1.02-1.05$ & 1.30 & $1.17-1.44$ & 1.90 & $1.38-2.62$ & $<0.001$ & $<0.001$ \\
\hline
\end{tabular}

Abbreviation: BMI, body mass index; RR, relative risk; $\mathrm{Cl}$, confidence interval.

* $P$ values for heterogeneity.

**P values for nonlinear.

doi:10.1371/journal.pone.0044522.t002

The possible reason reflected the gender difference might relate to the differences of hormone. Epidemiologic and animal studies have suggested that men have a higher incidence of liver cancer than women might be due to the stimulatory effects of androgen and the protective effects of estrogen [42]. A meta-analysis found that testosterone concentration were associated with a lower risk of diabetes in male but a higher risk in female [43]. Diabetes, as a closely correlated factor with obesity in metabolic syndrome, has been suggested to be independent risk factor of liver cancer. So the effect of hormone might be the reason for the stronger association of obesity with liver cancer in male than in female. The real causes for the gender difference still need to be explored.

There were also several limitations that might affect the interpretation of the results in our meta-analysis. First of all, restricted cubic splines required sufficient data to form polynomial models within each category of BMI. Unfortunately, there were insufficient data to permit a dose-response relationship in female, different ethnic group and measure method subgroups, affecting the power of the statistics. Secondly, some important confounders have not been measured with sufficient precision. Only some article had considered alcohol consumption, cigarette smoking, hepatitis infection status, dietary factors and physical activity. Lack of adjustment for these important risk factors limited the ability to generalize between obesity and liver cancer. Finally, BMI was the most commonly reported but not the best index to assess body adiposity; other anthropometric measures methods such as waisthip ratio and waist circumference [44] have been suggested to be more pertinent and sensitive disease predictors than BMI [45] However, few studies provided such information to permit comprehensive analysis of associations across studies.

Considerable evidence has accumulated to support links between obesity and increased risk of several types of cancer: postmenopausal breast, endometrium, kidney, colon, pancreas, gall-bladder and esophageal cancers [46], but the mechanisms linking both obesity and these common cancers are not yet fully understood. Recent studies have suggested that inflammation may be the primary potential mechanism linking obesity with liver cancer. Biological evidence indicated that high levels of interleukin 6 and tumor necrosis factor, which are associated with obesity, turned healthy cells into malignant ones through chronic lowgrade inflammation of the liver [47]. Moreover, inflammation was just one possible link between obesity and cancer. In addition, alcohol consumption, hepatitis viruses and many other factors probably also affected these cells [48]. Diabetes as an independent risk factor of liver cancer [8] was closely correlated with obesity. Both diabetes and obesity contribute to metabolic syndrome [49]. Some hypotheses have indicated that obesity is involved in metabolic abnormalities [50], in which insulin and insulin-like growth factors may distort the normal balance between determinants of cell proliferation, differentiation, and apoptosis, and thus may promote carcinogenesis [51]. Therefore, the biological mechanisms underlying the obesity-cancer link still need to be clarified.

\section{Conclusions}

The findings from meta-analysis provided accurate depiction of the role of BMI with liver cancer, suggesting that excess body mass index were associated with risk of liver cancer. Further, the correlation might differ across diverse ethnic backgrounds.

\section{Supporting Information}

\section{Figure S1 Flow chart of study selection.} (TIF)

Figure S2 The curve of body mass index and risk of liver cancer for male $(P$-heterogeneity $=0.005$; $P$-nonlinear $<0.001$ ).

(TIF)

Figure S3 The curve of body mass index and risk of liver cancer for directly measure BMI (P-heterogeneity $=0.032 ; P$-non-linear $<0.001$ ).

(TIF)

\section{Author Contributions}

Designed the study and directed its implementation, including extracting and analysis data and drafting of the manuscript: PR. Designed the study's analytic strategy, prepared the Materials and Methods, and drafted the manuscript: JL. Gave technical support and re-checked data: LZ RZ J.Wang DX QW HL J. Wu XL CL LL. Contributed significantly in data analysis: JX. Designed the study, analyzed and interpreted data, critically revised manuscript, and supervised the field activities: $\mathrm{XH}$. 


\section{References}

1. Bosch FX, Ribes J, Diaz M, Cleries R (2004) Primary liver cancer: worldwide incidence and trends. Gastroenterology 127: S5-S16.

2. Llovet JM, Burroughs A, Bruix J (2003) Hepatocellular carcinoma. Lancet 362: 1907-1917.

3. McGlynn KA, London WT (2005) Epidemiology and natural history of hepatocellular carcinoma. Best Pract Res Clin Gastroenterol 19: 3-23.

4. Polesel J, Zucchetto A, Montella M, Dal Maso L, Crispo A, et al. (2009) The impact of obesity and diabetes mellitus on the risk of hepatocellular carcinoma. Ann Oncol 20: 353-357.

5. Chuang SC, La Vecchia C, Boffetta P (2009) Liver cancer: descriptive epidemiology and risk factors other than $\mathrm{HBV}$ and $\mathrm{HCV}$ infection. Cancer Lett 286: 9-14.

6. Garcia-Compean D, Jaquez-Quintana JO, Gonzalez-Gonzalez JA, MaldonadoGarza H (2009) Liver cirrhosis and diabetes: risk factors, pathophysiology, clinical implications and management. World J Gastroenterol 15: 280-288.

7. Farrell GC, Larter CZ (2006) Nonalcoholic fatty liver disease: from steatosis to cirrhosis. Hepatology 43: S99-S112.

8. Gao C, Yao SK (2009) Diabetes mellitus: a "true" independent risk factor for hepatocellular carcinoma? Hepatobiliary Pancreat Dis Int 8: 465-473.

9. Parr CL, Batty GD, Lam TH, Barzi F, Fang X, et al. (2010) Body-mass index and cancer mortality in the Asia-Pacific Cohort Studies Collaboration: pooled analyses of 424,519 participants. Lancet Oncol 11: 741-752.

10. Kuriyama S, Tsubono Y, Hozawa A, Shimazu T, Suzuki Y, et al. (2005) Obesity and risk of cancer in Japan. Int J Cancer 113: 148-157.

11. Rapp K, Schroeder J, Klenk J, Stoehr S, Ulmer H, et al. (2005) Obesity and incidence of cancer: a large cohort study of over 145,000 adults in Austria. Br J Cancer 93: 1062-1067.

12. Calle EE, Rodriguez C, Walker-Thurmond K, Thun MJ (2003) Overweight, obesity, and mortality from cancer in a prospectively studied cohort of U.S. adults. N Engl J Med 348: 1625-1638.

13. Larsson SC, Wolk A (2007) Overweight, obesity and risk of liver cancer: a metaanalysis of cohort studies. Br J Cancer 97: 1005-1008.

14. Chen Y, Wang X, Wang J, Yan Z, Luo J (2012) Excess body weight and the risk of primary liver cancer: An updated meta-analysis of prospective studies. Eur J Cancer.

15. Renehan AG, Tyson M, Egger M, Heller RF, Zwahlen M (2008) Body-mass index and incidence of cancer: a systematic review and meta-analysis of prospective observational studies. Lancet 371: 569-578.

16. Aune D, Greenwood DC, Chan DS, Vieira R, Vieira AR, et al. (2012) Body mass index, abdominal fatness and pancreatic cancer risk: a systematic review and non-linear dose-response meta-analysis of prospective studies. Ann Oncol 23: $843-852$.

17. Larsson SC, Orsini N (2011) Coffee consumption and risk of stroke: a doseresponse meta-analysis of prospective studies. Am J Epidemiol 174: 993-1001.

18. Harrell FE Jr, Lee KL, Pollock BG (1988) Regression models in clinical studies: determining relationships between predictors and response. J Natl Cancer Inst 80: $1198-1202$.

19. Orsini N, Bellocco R, Greenland S (2006) Generalized least squares for trend estimation of summarized dose-response data. The stata journal 6: 40-57.

20. Higgins JP, Thompson SG (2002) Quantifying heterogeneity in a meta-analysis. Stat Med 21: 1539-1558.

21. DerSimonian R, Laird N (1986) Meta-analysis in clinical trials. Control Clin Trials 7: 177-188.

22. Orsini N, Greenland S (2011) A procedure to tabulate and plot results after flexible modeling of a quantitative covariate. The stata journal 11: 1-29.

23. Tobias A (1999) Assessing the influence of a single study in meta-analysis. Stata Technical Bulletin 8: 15-17.

24. Egger M, Davey Smith G, Schneider M, Minder C (1997) Bias in meta-analysis detected by a simple, graphical test. BMJ 315: 629-634.

25. Oh SW, Yoon YS, Shin SA (2005) Effects of excess weight on cancer incidences depending on cancer sites and histologic findings among men: Korea National Health Insurance Corporation Study. J Clin Oncol 23: 4742-4754.

26. Jee SH, Yun JE, Park EJ, Cho ER, Park IS, et al. (2008) Body mass index and cancer risk in Korean men and women. Int J Cancer 123: 1892-1896.

27. Batty GD, Shipley MJ, Jarrett RJ, Breeze E, Marmot MG, et al. (2005) Obesity and overweight in relation to organ-specific cancer mortality in London (UK): findings from the original Whitehall study. Int J Obes (Lond) 29: 1267-1274.
28. Nair S, Mason A, Eason J, Loss G, Perrillo RP (2002) Is obesity an independent risk factor for hepatocellular carcinoma in cirrhosis? Hepatology 36: 150-155.

29. Joshi S, Song YM, Kim TH, Cho SI (2008) Socio-economic status and the risk of liver cancer mortality: a prospective study in Korean men. Public Health 122: 1144-1151.

30. Hart CL, Batty GD, Morrison DS, Mitchell RJ, Smith GD (2010) Obesity, overweight and liver disease in the Midspan prospective cohort studies. Int J Obes (Lond) 34: 1051-1059.

31. Moller H, Mellemgaard A, Lindvig K, Olsen JH (1994) Obesity and cancer risk: a Danish record-linkage study. Eur J Cancer 30A: 344-350.

32. Wolk A, Gridley G, Svensson M, Nyren O, McLaughlin JK, et al. (2001) A prospective study of obesity and cancer risk (Sweden). Cancer Causes Control 12: 13-21.

33. Samanic C, Gridley G, Chow WH, Lubin J, Hoover RN, et al. (2004) Obesity and cancer risk among white and black United States veterans. Cancer Causes Control 15: 35-43.

34. Wang CS, Yao WJ, Chang TT, Wang ST, Chou P (2009) The impact of type 2 diabetes on the development of hepatocellular carcinoma in different viral hepatitis statuses. Cancer Epidemiol Biomarkers Prev 18: 2054-2060.

35. Chen CL, Yang HI, Yang WS, Liu CJ, Chen PJ, et al. (2008) Metabolic factors and risk of hepatocellular carcinoma by chronic hepatitis $\mathrm{B} / \mathrm{C}$ infection: a follow-up study in Taiwan. Gastroenterology 135: 111-121.

36. Ioannou GN, Splan MF, Weiss NS, McDonald GB, Beretta L, et al. (2007) Incidence and predictors of hepatocellular carcinoma in patients with cirrhosis. Clin Gastroenterol Hepatol 5: 938-945, 945 e931-934.

37. N'Kontchou G, Paries J, Htar MT, Ganne-Carrie N, Costentin L, et al. (2006) Risk factors for hepatocellular carcinoma in patients with alcoholic or viral $\mathrm{C}$ cirrhosis. Clin Gastroenterol Hepatol 4: 1062-1068.

38. Samanic C, Chow WH, Gridley G, Jarvholm B, Fraumeni JF Jr (2006) Relation of body mass index to cancer risk in 362,552 Swedish men. Cancer Causes Control 17: 901-909.

39. Yu MW, Shih WL, Lin CL, Liu CJ, Jian JW, et al. (2008) Body-mass index and progression of hepatitis B: a population-based cohort study in men. J Clin Oncol 26: $5576-5582$.

40. Kelly T, Yang W, Chen CS, Reynolds K, He J (2008) Global burden of obesity in 2005 and projections to 2030. Int J Obes (Lond) 32: 1431-1437.

41. Deurenberg P, Deurenberg-Yap M, Guricci S (2002) Asians are different from Caucasians and from each other in their body mass index/body fat per cent relationship. Obes Rev 3: 141-146.

42. Yeh SH, Chen PJ (2010) Gender disparity of hepatocellular carcinoma: the roles of sex hormones. Oncology 78 Suppl 1: 172-179.

43. Ding EL, Song Y, Malik VS, Liu S (2006) Sex differences of endogenous sex hormones and risk of type 2 diabetes: a systematic review and meta-analysis. JAMA 295: 1288-1299.

44. Pischon T, Lahmann PH, Boeing H, Friedenreich C, Norat T, et al. (2006) Body size and risk of colon and rectal cancer in the European Prospective Investigation Into Cancer and Nutrition (EPIC). J Natl Cancer Inst 98: 920-931.

45. Aune D, Greenwood DC, Chan DS, Vieira R, Vieira AR, et al. (2011) Body mass index, abdominal fatness and pancreatic cancer risk: a systematic review and non-linear dose-response meta-analysis of prospective studies. Ann Oncol.

46. Wiseman M (2008) The second World Cancer Research Fund/American Institute for Cancer Research expert report. Food, nutrition, physical activity, and the prevention of cancer: a global perspective. Proc Nutr Soc 67: 253-256.

47. Toffanin S, Friedman SL, Llovet JM (2010) Obesity, inflammatory signaling, and hepatocellular carcinoma-an enlarging link. Cancer Cell 17: 115-117.

48. Jenks S (2010) Researchers explore mechanisms that may link obesity and cancer. J Natl Cancer Inst 102: 519-521.

49. Takamatsu S, Noguchi N, Kudoh A, Nakamura N, Kawamura T, et al. (2008) Influence of risk factors for metabolic syndrome and non-alcoholic fatty liver disease on the progression and prognosis of hepatocellular carcinoma. Hepatogastroenterology 55: 609-614.

50. Yang S, Lin HZ, Hwang J, Chacko VP, Diehl AM (2001) Hepatic hyperplasia in noncirrhotic fatty livers: is obesity-related hepatic steatosis a premalignant condition? Cancer Res 61: 5016-5023.

51. Giovannucci E (2003) Nutrition, insulin, insulin-like growth factors and cancer. Horm Metab Res 35: 694-704. 